Cardiology in the Young

http://journals.cambridge.org/CTY

Additional services for Cardiology in the Young:

Email alerts: Click here

Subscriptions: $\underline{\text { Click here }}$

Commercial reprints: $\underline{\text { Click here }}$

Terms of use : $\underline{\text { Click here }}$

\title{
Determinants of physical activity in young adults with tetralogy of Fallot
}

Roselien Buys, Werner Budts, Christophe Delecluse and Luc Vanhees

Cardiology in the Young / FirstView Article / November 2012, pp 1 - 7

DOI: $10.1017 / \mathrm{S} 1047951112001898$, Published online:

Link to this article: http://journals.cambridge.org/abstract S1047951112001898

How to cite this article:

Roselien Buys, Werner Budts, Christophe Delecluse and Luc Vanhees Determinants of physical activity in young adults with tetralogy of Fallot. Cardiology in the Young, Available on CJO doi:10.1017/S1047951112001898

Request Permissions : $\underline{\text { Click here }}$ 


\title{
Determinants of physical activity in young adults with tetralogy of Fallot
}

\author{
Roselien Buys, ${ }^{1}$ Werner Budts, ${ }^{2}$ Christophe Delecluse, ${ }^{3}$ Luc Vanhees ${ }^{1}$ \\ ${ }^{1}$ Department of Rehabilitation Sciences, Research Center for Cardiovascular and Respiratory Rehabilitation, \\ University of Leuven, Tervuursevest; ${ }^{2}$ Department of Cardiology, University Hospital Gastbuisberg; ${ }^{3}$ Department of \\ Biomedical Kinesiology, Research Centre for Exercise and Health, University of Leuven, Leuven, Belgium
}

\begin{abstract}
Background: Although sports participation is allowed to most adult patients with corrected tetralogy of Fallot, a reduced exercise tolerance and reduced perceived physical functioning is often present in these patients. We aimed to investigate daily physical activity in adults with tetralogy of Fallot and to investigate the underlying determinants of physical activity in daily life. Methods: We studied 73 patients with tetralogy of Fallot (53 male; mean age $27.3 \pm 7.9$ years) who underwent echocardiography and cardiopulmonary exercise testing, and who completed questionnaires about physical activity and perceived health status. All variables were compared with data from a general population. Relationships were studied by Pearson or Spearman correlation coefficients with correction for multiple testing. Results: Patients were significantly less active compared with the general population ( $\mathrm{p}>0.05), 55 \%$ of all patients were sedentary, $27 \%$ had an active or moderately active lifestyle, and $18 \%$ of the group had a vigorously active lifestyle. Peak oxygen uptake $(71 \pm 16 \% ; \mathrm{p}<0.0001)$ was significantly reduced and related to reduced physical activity levels $(\mathrm{r}=0.229 ; \mathrm{p}=0.017)$ and perceived physical functioning $(\mathrm{r}=0.361 ; \mathrm{p}=0.002)$. Conclusions: Adult patients with tetralogy of Fallot have a sedentary lifestyle and are less active than the general population. Inactivity significantly contributes to reduced exercise capacity, in addition to the impairment based on the cardiac condition. Moreover, reduced exercise capacity and the intensity of sports performed in daily life are related to perceived physical functioning. Individual patient counselling on physical activity might be a low-cost, high-benefit measure to be taken in this patient population.
\end{abstract}

Keywords: Tetralogy of Fallot; physical activity; exercise capacity; short form 36

Received: 3 May 2012; Accepted: 28 September 2012

$\mathrm{O}$ WING TO THE ONGOING IMPROVEMENT OF LIFE expectancy, the number of grown-up patients with congenital heart disease is generally increasing, and more and more patients receive tertiary care in specialised centres for adult congenital heart disease. ${ }^{1}$ Tetralogy of Fallot accounts for about $5 \%$ of all congenital heart diseases and is the most common cyanotic congenital heart disease. ${ }^{2}$

Physical activity guidelines allow adults who underwent successful surgical correction for tetralogy

Correspondence to: R. Buys, PhD, Department of Rehabilitation Sciences, Research Center for Cardiovascular and Respiratory Rehabilitation, University of Leuven, Tervuursevest 101 - bus 1501, B-3001 Heverlee, Belgium. Tel: +32 486388176; Fax: +32 16 329197; E-mail: Roselien.Buys@faber.kuleuven.be of Fallot to perform low to moderate dynamic and static sports. ${ }^{3}$ All competitive sports are allowed in patients with an excellent repair and clinical status. If not, patients are instructed to participate only in low-intensity competitive sports. ${ }^{4}$ Normal to severely reduced physical activity levels in adults with congenital heart disease have been reported recently. ${ }^{5,6}$ However, data regarding physical activity levels or attitudes towards exercise focussing specifically on adults with tetralogy of Fallot are lacking but seem important, as adult patients with tetralogy of Fallot do need to accept certain exercise restrictions, but they generally do not feel limited. As a consequence, a patient with tetralogy of Fallot who is not adequately informed about physical 
exercise with his condition might remain inactive because he is too scared to exercise, or, on the other hand, he might be too active and cross the limits of safe exercise.

Despite very good outcomes from surgical correction and the allowance to be physically active, researchers report a significantly reduced exercise capacity as assessed by peak oxygen uptake compared with healthy persons of similar age and gender. ${ }^{7-9}$ Different mechanisms underlying this reduced peak oxygen uptake in tetralogy of Fallot have been previously investigated, but to our knowledge the extent to which physical activity levels contribute to the reduced exercise capacity has hardly been studied.

Furthermore, although adult patients with tetralogy of Fallot or other congenital heart diseases generally experience a good health status, poorer perceived physical functioning and perceived general health has been reported, which is correlated with exercise capacity. ${ }^{10-12}$

Therefore, our aim was to investigate physical activity behaviour and perceived health status in adults with corrected tetralogy of Fallot and to investigate determinants of physical activity in daily life.

\section{Materials and methods}

Between 2009 and 2010, all patients with tetralogy of Fallot who were scheduled for their routine follow-up appointment at our outpatient clinic were also scheduled for cardiopulmonary exercise testing. We excluded study patients with other cardiac defects for which surgical intervention was needed and only included patients who terminated the exercise test because of exhaustion, as defined by shortness of breath and/or fatigue of the legs. In all, 74 consecutive patients who performed the exercise test until exhaustion were recruited for the study and were asked to complete the paper version of the Flemish Physical Activity Computerized Questionnaire about physical activity in their daily life and the short form 36 about their health status. All patients were between 16 and 46 years of age. There was one patient who was not mentally able to fill in the questionnaires, as assessed by the parents, and thus was excluded from the study. The study was approved by the Ethical Committee of the University Hospitals Leuven.

Maximal cardiopulmonary exercise tests on a bicycle ergometer (Ergometrics 800S, Ergometrics, Bitz, Baden-Württemberg, Germany) were performed in a laboratory in which the temperature was stabilised at $18-22^{\circ} \mathrm{C}$. The initial workload of $20 \mathrm{~W}$ was increased by $20 \mathrm{~W}$ every minute until exhaustion, as defined by shortness of breath and/or fatigue of the legs, was reached. Systolic and diastolic blood pressures were measured at rest and every 2 min during the exercise test. Heart rate was calculated from the continuously registered 12-lead electrocardiogram (Max Personal Exercise Testing ${ }^{\circledR}$, Marquette, Wisconsin, United States of America), and respiratory data were continuously measured through breath-by-breath analysis (Oxygen Alpha ${ }^{\circledR}$, Jaeger, Mijnhardt, Bunnik, The Netherlands). Before each test, the gas analysers and the flowmeter were calibrated according to the manufacturer's instructions. During the exercise test, oxygen uptake and carbon dioxide production were determined from the continuous measurement of oxygen and carbon dioxide concentration in the inspired and expired air. Peak oxygen uptake was defined as the highest 30-s average of oxygen uptake at the end of the test. The percentage of predicted peak oxygen uptake (peak oxygen uptake\%) was calculated as peak oxygen uptake divided by the maximal predicted oxygen uptake, using the values reported by Wasserman and Whipp. ${ }^{13}$ Exercise testing data were compared with data from a control group of apparently healthy subjects of similar age who performed the same exercise testing protocol at the same laboratory.

Routine transthoracic echocardiography was performed with standard gray-scale, and Doppler imaging examinations using a Vivid 7 or 9 ultrasound system (General Electric Vingmed Ultrasound, Horten, Norway) equipped with a 3-MHz transducer. All echocardiographic studies were performed with the participant in the supine position.

Qualitative evaluations were used for the evaluation of right ventricular hypertrophy $(0=$ no hypertrophy, 1 = hypertrophy), right ventricular dilatation (no, slight, moderate, and severe dilatation, scaling from 1 to 4 ), right ventricular contractility (normal, mild, moderate, and severe dysfunction, scaling from 1 to 4 ), pulmonary valve insufficiency, and tricuspid valve insufficiency.

A postal survey was used to collect information regarding physical activity and perceived health status. Patients who did not return their questionnaires by post were asked to complete them during the next follow-up visit at the outpatient clinic (maximum 1 year later).

Self-reported physical activity was assessed by the Flemish Physical Activity Computerized Questionnaire. This questionnaire indicates how long and according to which intensity the patients are involved in different physical activities during a usual week in a usual year. The Flemish Physical Activity Computerized Questionnaire is a reliable and valid questionnaire about regular physical activity. ${ }^{14}$ Reference values from the Policy Research Centre Sport, Physical Activity and Health (based on 1170 Flemish men and women between 18 and 75 years) were used for 
comparative purposes. ${ }^{15}$ Health-related sports participation was based on all sports of which the associated metabolic equivalent was at least 4.5 for patients younger than 35 years old, or at least 4.0 for patients older than 35 years old. ${ }^{16}$

The short form 36 health survey questionnaire was used to evaluate the general health perception. The short form 36 is an eight-scale profile, which provides a score between 0 and 100 for following eight subscales: physical and social functioning, role limitations attributed to physical and emotional problems, mental health, vitality (energy/fatigue), pain, and general health perception. Higher scores indicate a better health perception. This questionnaire has previously been used in adult populations with congenital heart disease. ${ }^{10,11,17}$ The validity of the Dutch version of the questionnaire was showed by Aaronson et al. ${ }^{18}$ Their reference values (1742 adults; $56 \%$ male; mean age $47.6 \pm 18$ years; age range 16-94 years) were used for comparison with a general population. ${ }^{18}$

Statistical Analysis Software version 9.3 was used for data analysis (SAS Institute Inc., Cary, North Carolina, United States of America). Data are reported as means \pm standard deviation, as median (range), or as numbers for dichotomous variables. The Shapiro-Wilk statistic was used to check the normality.

Exercise testing data were compared with data from 196 healthy adults of similar age, gender, and body mass index by Student's unpaired t-test. Possible determinants of physical activity were investigated by Pearson and Spearman correlation coefficients. The following variables were investigated: demographic characteristics, clinical characteristics, educational level, employment status, marital status, and all fields of perceived health status. Results from the questionnaires were compared with reference values, according to age and gender, by calculation of mean standardised differences. For each patient, the score of the reference group was subtracted from the patient's score and this was divided by the standard deviation of the reference group, generating a standardised difference for that patient. The average of the patients' values resulted in a mean standardised difference. The one sample t-test was used to evaluate whether the mean standardised differences significantly differed from zero. All statistical tests were two sided at a significance level of 0.05 . Correction for multiple testing was applied according to the false discovery rate method of Benjamini. ${ }^{19}$

\section{Results}

Patients' mean age was $27.3 \pm 7.9$ years and ranged between 16 and 46 years. Demographic characteristics
Table 1. Demographic and clinical characteristics $(n=73)$.

\begin{tabular}{ll}
\hline Demographic and clinical variables & \\
Male gender & $53(73)$ \\
Age (years) & $27.3 \pm 7.9$ \\
Body mass index $\left(\mathrm{kg} / \mathrm{m}^{2}\right)$ & $22.6 \pm 3.7$ \\
Resting systolic blood pressure $(\mathrm{mmHg})$ & $125 \pm 17$ \\
Resting heart rate $(\mathrm{bpm})$ & $80 \pm 13$ \\
$\quad$ QRS duration (ms) & $147 \pm 27$ \\
Surgical characteristics & $5.8(0.6-27)$ \\
$\quad$ Age at total correction (years) & $34(47)$ \\
Previous palliative surgery & $39(53)$ \\
$\quad$ Correction with transannular patch & $30(41)$ \\
Pulmonary valve replacement & \\
Echocardiographic variables & $48 / 21 / 4$ \\
RV contractility (normal/slightly/moderately & \\
$\quad$ reduced) & $13 / 39 / 21$ \\
RV dilatation (no/slight/moderate dilatation) & \\
RV hypertrophy (no hypertrophy/hypertrophy) & $57 / 16$ \\
\hline
\end{tabular}

$\mathrm{RV}=$ right ventricle.

and clinical characteristics are summarised in Table 1. Of all patients, 34 underwent palliative surgery. Final correction was established in 29 patients with a valvotomy, in 39 patients with a transannular patch, and in five patients with a homograft.

A summary of all data concerning physical activity can be found in Table 2. In all, 55\% of all patients were involved in sports activities, most often fitness, swimming, jogging, cycling, and football. Of this group, seven patients $(10 \%)$ were involved in competition $(3 \times$ football, $1 \times$ tennis, $1 \times$ skateboarding, $1 \times$ dressage, $1 \times$ fishing). Time spent in sports ranged from 0 to $20 \mathrm{~h} /$ week. In addition, if activities such as housekeeping, gardening, and walking/biking for transportation were taken into account, patients spent between 0.5 and $46 \mathrm{~h}$ in active leisure time. Total energy expenditure, volume of health-related sports, and volume of active leisure time were significantly lower compared with the general population (see Fig 1).

On the basis of the classification of physical activity levels of the World Health Organisation, $55 \%$ of all patients were sedentary, $27 \%$ had an active or moderately active lifestyle, and $18 \%$ of the group had a vigorously active lifestyle. Out of all investigated determinants of physical activity, only body mass index was weakly correlated with the volume of health-related sports $(r=0.263$; $\mathrm{p}=0.026)$.

Table 3 lists all exercise data. Mean peak oxygen uptake was $28.3 \pm 7.80 \mathrm{ml} / \mathrm{min} / \mathrm{kg}$ or $71 \pm 16 \%$ of predicted values, which is significantly lower than expected in a general population $(\mathrm{p}<0.0001)$. Significant correlations were found between peak oxygen uptake and reported measures of physical activity in daily life (see Table 2 and Fig 2). 
Table 2. Daily physical activity measures and correlation with peak oxygen uptake.

\begin{tabular}{lccc}
\hline Physical activity measures & Median (range) & r & \multicolumn{1}{c}{ p-value } \\
\hline Volume of active leisure time/week (METh) & $40.3(3.24-154)$ & 0.202 & $\mathrm{~ns}$ \\
Duration of active leisure time/week (h/week) & $12.3(2.15-44.4)$ & 0.12 & $\mathrm{~ns}$ \\
Intensity of active leisure time (METs) & $3.16(1.30-5.18)$ & 0.323 & 0.0008 \\
Volume of sports/week (METh) & $0(0-90)$ & 0.293 \\
Duration of sports/week (h/week) & $0(0-14)$ & 0.273 \\
Intensity of sports/week (METS) & $0(0-10.7)$ & 0.229 & 0.0030 \\
Physical activity level (METs) & $1.68(1.30-2.172)$ & 0.229 & 0.0051 \\
Total energy expenditure (METh) & $282(218-365)$ & -0.241 & 0.0170 \\
Duration of passively spent leisure time (h) & $57(21-106)$ & 0.0170 \\
\hline
\end{tabular}

METs $=$ metabolic equivalent of tasks; ns $=$ not significant

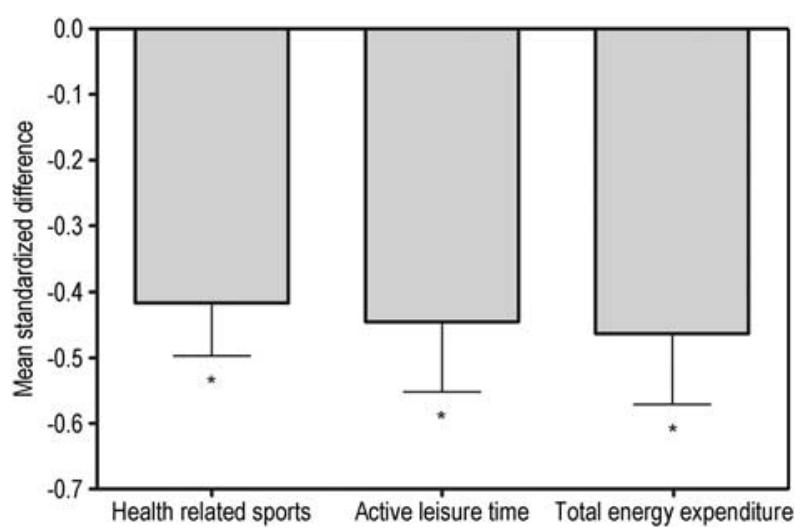

Figure 1.

Mean standardised differences of physical activity measures in comparison with healthy counterparts. *Statistically different from $0(p<0.0001)$.

Perceived health status scores are shown in Figure 3. Perceived physical functioning, general health, vitality, and mental health were significantly lower than the healthy reference population. Perceived physical functioning was weakly correlated with peak oxygen uptake $(\mathrm{r}=0.361 ; \mathrm{p}=0.002$; Fig 2) and the intensity of health-related sports/week $(\mathrm{r}=0.271 ; \mathrm{p}=0.023)$.

\section{Discussion}

Patients with tetralogy of Fallot report lower physical activity levels compared with the general population and show a significantly lower exercise tolerance than healthy persons. Furthermore, adult patients with tetralogy of Fallot report lower scores in the fields of physical functioning, vitality, general health, and mental health compared with the general population. Parameters of daily physical activity are related with perceived physical functioning and show relationships with exercise capacity. Patients with a higher level of physical activity in daily life have a higher body mass index.

To the best of our knowledge, this is the first study that investigates determinants of physical activity in daily life in adult patients with tetralogy of Fallot. First, our results show that adult patients with tetralogy of Fallot are significantly less active compared with the general population. The World Health Organization states that a desirable physical activity level includes the regular practice of physical activity at work or during leisure time with an intensity and duration that will reduce the risk of becoming overweight and developing a variety of non-communicable chronic diseases usually associated as comorbidities with obesity. This corresponds to physical activity levels of 1.75 and higher. ${ }^{20}$ Our study shows that a large part of patients with tetralogy of Fallot did not reach this recommendation. Reduced physical activity levels have previously been reported in adolescents and adults with congenital heart disease. ${ }^{5,6,21}$ Reasons for reduced daily physical activity seem to be overprotection by the environment, fear for adverse reactions or sudden death triggered by exercising, and insufficient or unclear information given by the patients' healthcare providers. ${ }^{22-24}$ Indeed, adult patients with tetralogy of Fallot need to take certain guidelines on physical activity into account; however, they are not entirely restricted from physical exercise. ${ }^{3}$ Moreover, Therrien et $\mathrm{al}^{25}$ showed that a moderately intense exercise training programme seems to be safe and has beneficial effects on the exercise capacity in clinically stable patients with tetralogy of Fallot. Furthermore, our study now provides evidence for the relationship of low physical activity levels with reduced exercise capacity of adult patients with tetralogy of Fallot. It has already been suggested that the reduced exercise tolerance could be explained by the fact that adults with congenital heart disease have a low level of daily physical activity; however, this was not 
Table 3. Exercise variables in comparison with healthy controls.

\begin{tabular}{lccc}
\hline & TOF & CON & p-value \\
\hline Exercise duration (min) & $7.98 \pm 2.92$ & $11.7 \pm 3.73$ & $<0.0001$ \\
Peak oxygen uptake (ml/min/kg) & $28.5 \pm 7.61$ & $39.3 \pm 8.76$ & $<0.0001$ \\
Peak oxygen uptake $\%$ of predicted) & $71 \pm 16^{*}$ & $102 \pm 18$ & $<0.0001$ \\
Peak heart rate (bpm) & $167 \pm 23$ & $183 \pm 17$ & $<0.0001$ \\
Peak ventilation & $69.9 \pm 23.9$ & $102 \pm 30$ & $<0.0001$ \\
Peak oxygen pulse & $11.6 \pm 3.35$ & $15.5 \pm 6.96$ & $<0.0001$ \\
VE/VCO $\mathrm{VCl}_{2}$-slope & $27.7 \pm 9.38$ & $24.9 \pm 4.08$ & 0.023 \\
\hline
\end{tabular}

$\mathrm{CON}=$ control group; $\mathrm{TOF}=$ tetralogy of Fallot; $\mathrm{VE} / \mathrm{VCO}_{2}=$ ventilatory efficiency

Measures are expressed as mean \pm standard deviation

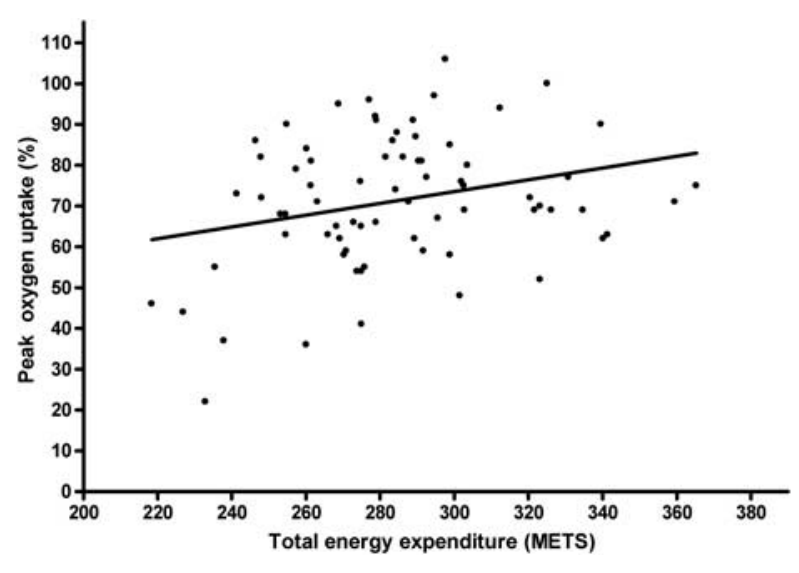

Figure 2.

Relationship of percentage of predicted peak oxygen uptake with total energy expenditure in daily life $(r=0.229 ; p=0.017)$. METS = metabolic equivalent of tasks.

based on an evaluation of physical activity levels. ${ }^{8}$ Muller et $\mathrm{al}^{6}$ showed this relation in a large group of adults with various congenital heart conditions. It remains to be further investigated whether physical activity increases cardiopulmonary exercise capacity or whether patients with a better cardiopulmonary condition are more likely to be physically active.

Second, we investigated which other variables are related with physical activity in daily life. We did not find any differences in physical activity levels according to demographic, clinical, and educational characteristics. We only found a relationship between body mass index and volume of healthrelated physical activity in daily life. It might seem contradicting that patients with a higher body mass index are more active in daily life. However, as most patients with tetralogy of Fallot are generally rather thin, this probably reflects a higher muscle mass in the more physically active part of our study group.

Third, we evaluated the patients' perceived health status by the short form 36 questionnaire. Lower scores compared with the normal population in the fields of physical functioning and general health

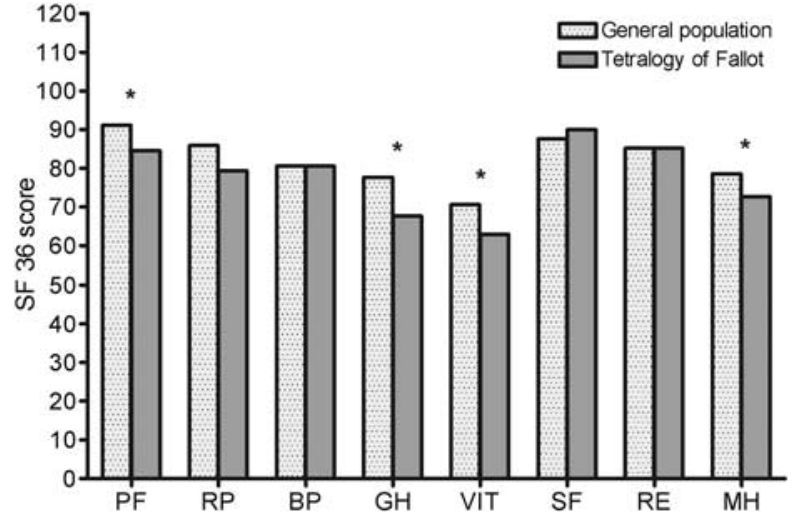

Figure 3 .

Mean short form 36 scores in patients with tetralogy of Fallot compared with the general population. *Significant difference between general population and patients with tetralogy of Fallot $(p<0.05) . B P=$ bodily pain, $G H=$ general health, $M H=$ mental health, $P F=$ physical functioning, $R E=$ role-emotional functioning, $R P=$ role-physical functioning, $S F=$ social functioning, VIT = vitality.

have previously been reported and our results are consistent with these findings. ${ }^{10,11,26,27}$ Perceived physical functioning was correlated with objective exercise capacity, even though many patients overestimated their physical functioning. This phenomenon has been mentioned before and can be attributed to the fact that these patients have always had their cardiac problem and therefore their limitations seem normal for them. ${ }^{10}$ Furthermore, we found reductions in perceived vitality and mental health. It seems that the cardiac condition, even if optimally treated, causes the patient to feel tired and somehow limited, leading not only to physical limitations but to emotional problems as well.

Regular follow-up in order to keep the adult patient with tetralogy of Fallot healthy is the primary goal of the tertiary care centre for adult congenital heart disease. Patients therefore undergo regular medical check-ups including clinical examination, electrocardiography, cardiac imaging, and 
exercise testing. Furthermore, it is generally accepted that most adult patients with congenital heart disease should be stimulated to be physically active at an appropriate intensity, especially when it is taken into account that a reduced exercise capacity is related to a worse long-term prognosis of patients with tetralogy of Fallot. ${ }^{28}$ We therefore believe that the incorporation of individual patient counselling on physical activity, based on the advice of the patients' cardiologist and performed by adequately trained physiotherapists or exercise scientists, might be a low-cost, high-benefit measure that will probably improve the patient's objective exercise tolerance and perceived health status, improve outcome and reduce the risk of the early development of cardiovascular and other diseases associated with inactivity. ${ }^{29}$

Some limitations of the present study should be recognised. We evaluated a small study group in a single-centre design. Our results should therefore be interpreted with caution when applied to the general population of adult patients with tetralogy of Fallot. Second, levels of physical activity were subjectively assessed by questionnaires and might therefore be overestimated and not comparable with results from objective measurements of physical activity.

\section{Conclusions}

In conclusion, adult patients with tetralogy of Fallot are less engaged in physical activities compared with the general population. This sedentary lifestyle seems to contribute significantly to reduced exercise capacity of adult patients with tetralogy of Fallot, in addition to the impairment based on the cardiac condition. Moreover, reduced exercise capacity and the intensity of sports performed in daily life are related with perceived physical functioning in daily life. Individual patient counselling on physical activity might be a low-cost, high-benefit measure to be taken in this patient population.

\section{Acknowledgements}

The authors greatly appreciate the work of Jan Meertens and Dirk Schepers in the exercise testing laboratory, as well as the help of Sonia Rens and Sara Van Damme with the collection of the questionnaires.

\section{References}

1. Moons P, Sluysmans T, De Wolf D, et al. Congenital heart disease in 111,225 births in Belgium: birth prevalence, treatment and survival in the 21st century. Acta Paediatr 2009; 98: 472-477.

2. van der Linde D, Konings EE, Slager MA, et al. Birth prevalence of congenital heart disease worldwide: a systematic review and meta-analysis. J Am Coll Cardiol 2011; 58: 2241-2247.
3. Takken T, Giardini A, Reybrouck T, et al. Recommendations for physical activity, recreation sport, and exercise training in paediatric patients with congenital heart disease: a report from the Exercise, Basic \& Translational Research Section of the European Association of Cardiovascular Prevention and Rehabilitation, the European Congenital Heart and Lung Exercise Group, and the Association for European Paediatric Cardiology. 2012. DOI: $10.1177 / 1741826711420000$.

4. Graham TP Jr, Bricker JT, James FW, Strong WB. 26th Bethesda conference: recommendations for determining eligibility for competition in athletes with cardiovascular abnormalities. Task Force 1: congenital heart disease. J Am Coll Cardiol 1994; 24: 867-873.

5. Dua JS, Cooper AR, Fox KR, Graham SA. Physical activity levels in adults with congenital heart disease. Eur J Cardiovasc Prev Rehabil 2007; 14: 287-293.

6. Muller J, Hess J, Hager A. Daily physical activity in adults with congenital heart disease is positively correlated with exercise capacity but not with quality of life. Clin Res Cardiol 2012; 101: 55-61.

7. Diller GP, Dimopoulos K, Okonko D, et al. Exercise intolerance in adult congenital heart disease: comparative severity, correlates, and prognostic implication. Circulation 2005; 112: 828-835.

8. Fredriksen PM, Veldtman G, Hechter S, et al. Aerobic capacity in adults with various congenital heart diseases. Am J Cardiol 2001; 87: 310-314.

9. Buys R, Cornelissen V, Van De Bruaene A, et al. Measures of exercise capacity in adults with congenital heart disease. Int $\mathrm{J}$ Cardiol 2011; 153: 26-30.

10. Hager A, Hess J. Comparison of health related quality of life with cardiopulmonary exercise testing in adolescents and adults with congenital heart disease. Heart 2005; 91: 517-520.

11. Gratz A, Hess J, Hager A. Self-estimated physical functioning poorly predicts actual exercise capacity in adolescents and adults with congenital heart disease. Eur Heart J 2009; 30: 497-504.

12. Daliento L, Mapelli D, Russo G, et al. Health related quality of life in adults with repaired tetralogy of Fallot: psychosocial and cognitive outcomes. Heart 2005; 91: 213-218.

13. Wasserman K, Whipp BJ. Excercise physiology in health and disease. Am Rev Respir Dis 1975; 112: 219-249.

14. Matton L, Wijndaele K, Duvigneaud N, et al. Reliability and validity of the flemish physical activity computerized questionnaire in adults. Res Q Exerc Sport 2007; 78: 293-306.

15. Scheers T, Philippaerts R, Van Langendonck L, et al. Lipid profile in men and women with different levels of sports participation and physical activity. Public Health Nutr 2008; 11: 1098-1106.

16. Scheers T, Philippaerts R, Lefevre J. Variability in physical activity patterns as measured by the SenseWear Armband: how many days are needed? Eur J Appl Physiol 2012; 112(5): 1653-1662.

17. Kamphuis M, Ottenkamp J, Vliegen HW, et al. Health related quality of life and health status in adult survivors with previously operated complex congenital heart disease. Heart 2002; 87: 356-362.

18. Aaronson NK, Muller M, Cohen PD, et al. Translation, validation, and norming of the Dutch language version of the SF-36 Health Survey in community and chronic disease populations. J Clin Epidemiol 1998; 51: 1055-1068.

19. Benjamini Y, Drai D, Elmer G, Kafkafi N, Golani I. Controlling the false discovery rate in behavior genetics research. Behav Brain Res 2001; 125: 279-284.

20. FAO/WHO/UNU. Human energy requirements. Report of a Joint FAO/WHO/UNU Expert Consultation. FAO Food and Nutrition Technical Report Series No. 1, Rome, 17 October 2001.

21. Lunt D, Briffa T, Briffa NK, Ramsay J. Physical activity levels of adolescents with congenital heart disease. Aust J Physiother 2003; 49: 43-50.

22. Reybrouck T, Mertens L. Physical performance and physical activity in grown-up congenital heart disease. Eur J Cardiovasc Prev Rehabil 2005; 12: 498-502. 
23. Caplan R, Allen PJ. Physical activity recommendations for adolescents with repaired tetralogy of Fallot: review of the literature and guidelines for practitioners. Pediatr Nurs 2011; 37: 191-199.

24. Harrison JL, Silversides CK, Oechslin EN, Kovacs AH. Healthcare needs of adults with congenital heart disease: study of the patient perspective. J Cardiovasc Nurs 2011; 26: 497-503.

25. Therrien J, Fredriksen P, Walker M, Granton J, Reid GJ, Webb G. A pilot study of exercise training in adult patients with repaired tetralogy of Fallot. Can J Cardiol 2003; 19: 685-689.

26. Lane DA, Lip GY, Millane TA. Quality of life in adults with congenital heart disease. Heart 2002; 88: 71-75.
27. Lu JC, Cotts TB, Agarwal PP, Attili AK, Dorfman AL. Relation of right ventricular dilation, age of repair, and restrictive right ventricular physiology with patient-reported quality of life in adolescents and adults with repaired tetralogy of Fallot. Am J Cardiol 2010; 106: 1798-1802.

28. Giardini A, Specchia S, Tacy TA, et al. Usefulness of cardiopulmonary exercise to predict long-term prognosis in adults with repaired tetralogy of Fallot. Am J Cardiol 2007; 99: 1462-1467.

29. Booth FW, Laye MJ, Roberts MD. Lifetime sedentary living accelerates some aspects of secondary aging. J Appl Physiol 2011; 111: 1497-1504. 